\title{
Aldosterone- and cortisol-co-secreting adrenal adenoma in an adolescent girl: a case report
}

\author{
Serap Baydur Sahin ${ }^{1}$, Ahmet Hamdi Aktan², Osman Zikrullah Sahin ${ }^{3}$, Ahmet Fikret Yucel ${ }^{4}$, Teslime Ayaz², Ekrem Algun ${ }^{1}$ \\ ${ }^{1}$ Recep Tayyip Erdogan University Medical School, Department of Endocrinology and Metabolism Disease, Rize, Turkey \\ ${ }^{2}$ Recep Tayyip Erdogan University Medical School, Department of Internal Medicine, Rize, Turkey \\ ${ }^{3}$ Recep Tayyip Erdogan University Medical School, Department of Nephrology, Rize, Turkey \\ ${ }^{4}$ Recep Tayyip Erdogan University Medical School, Department of General Surgery, Rize, Turkey
}

Primary aldosteronism (PA) is the most common reason for secondary hypertension. Among adrenal disorders, rarely aldosterone- and cortisol-co-secreting adenomas (A/CPA) can lead to PA. 35 patients with A/CPA were reported to date and their mean age was 52 (range 34-80) years. We report an $\mathrm{A} / \mathrm{CPA}$ in an adolescent girl presenting with hypertension combined with hypokalemia and signs of hypercortisolism.

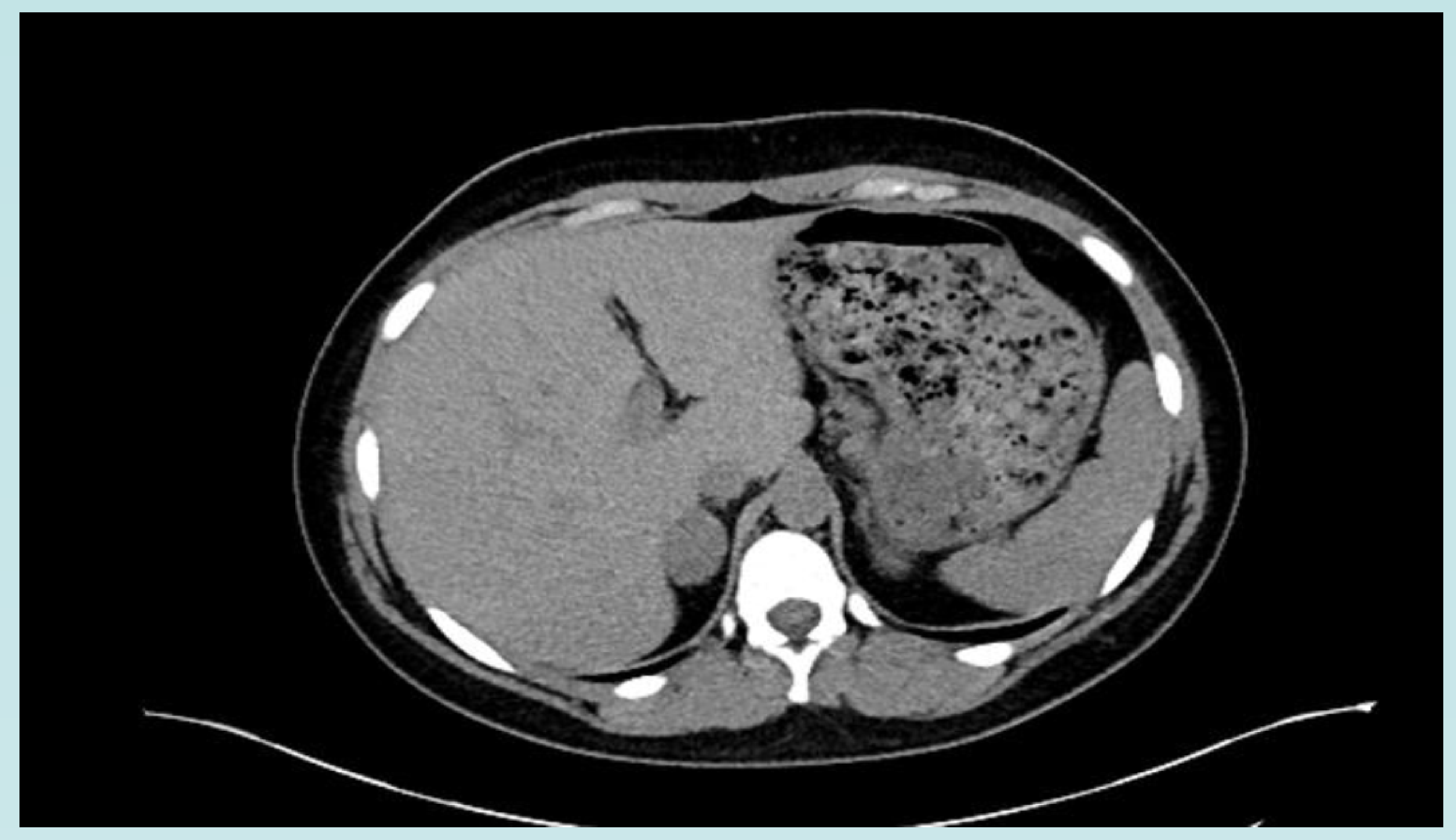

Figure 1 Computed tomography of adrenal glands shows a $24 \times 14 \mathrm{~mm}$ hypodense solid lesion in the right adrenal gland

A 18-year-old girl admitted to endocrinology outpatient clinic with the complaint of hypertension. Physical examination revealed central obesity (BMI:31 kg/m²), moon face, hirsutism, buffalo hump and abdominal striae. Her blood pressure was $170 / 110 \mathrm{mmHg}$. Laboratory examination revealed serum potassium level of $2.4 \mathrm{mEq} / \mathrm{L}$. The mean aldosterone to renin ratio was 308 (aldosterone: $98.77 \mathrm{ng} / \mathrm{dl}$, plasma renin activity (PRA): $0.32 \mathrm{ng} / \mathrm{mL} /$ hour). Intravenous saline infusion test was performed as the confirmatory test. Her post-infusion aldosterone level was $80.69 \mathrm{ng} / \mathrm{dL}$. While the midnight serum cortisol level was $7.6 \mathrm{~g} / \mathrm{dL}$, her serum cortisol levels failed to suppress during a $1 \mathrm{mg}$ dexamethasone suppression test (DST) $(5 \mathrm{~g} / \mathrm{dL})$ and $2 \mathrm{mg} \mathrm{DST}(9.8 \mathrm{~g} / \mathrm{dL})$. Serum ACTH and DHEA-S levels were $13.1 \mathrm{pg} / \mathrm{ml}$ and $11.12 \mathrm{~g} / \mathrm{dL}(\mathrm{N}:$ 65-368) respectively. Computed tomography of adrenal glands revealed a $24 \times 14 \mathrm{~mm}$ hypodense solid lesion in the right adrenal gland (Figure 1). She underwent laparoscopic right adrenalectomy with perioperative steroid replacement. At the postoperative day 4 at 08:00 $\mathrm{h}$, serum cortisol level was $0.6 \mathrm{~g} / \mathrm{dL}$ and she was put on substitution therapy with oral glucocorticoids. The aldosterone level and PRA were $2.12 \mathrm{ng} / \mathrm{dl}$ and $5.59 \mathrm{ng} / \mathrm{ml} / \mathrm{hour} 2$ days after the operation, respectively. At the follow-up, her blood pressure and serum potassium level returned to normal. screening of cortisol co-secretion in patients with aldosterone-producing adenomas is important to prevent adrenal crises at the perioperative period. 